\title{
KENTSEL DÖNÜŞÜM UYGULAMALARINDA YAPISAL ATIK SORUNU VE ÇÖZÜME YÖNELIK ÖNERILER: KAYSERİ ÖRNEĞİ
}

\author{
Burcu SALGIN (ORCID: 0000-0001-6473-5549) ${ }^{\mathbf{1}^{*}}$ \\ Nilay COŞGUN (ORCID: 0000-0001-5874-3331) ${ }^{2}$ \\ ${ }^{1}$ Mimarlık Bölümü, Mimarlık Fakültesi, Erciyes Üniversitesi, Kayseri, Türkiye \\ ${ }^{2}$ Mimarlık Bölümü, Mimarlık Fakültesi, Gebze Teknik Üniversitesi, Kocaeli, Türkiye
}

Gelis / Received: 07.08 .2017 Kabul / Accepted: 15.11.2017

\begin{abstract}
ÖZ
Kentsel yenileme, iyileştirme ve canlandırma yöntemleri kullanılarak uygulanan kentsel dönüşüm projeleri dünyada ve Türkiye'de hızla devam etmektedir. Bu projeler bir kent için yenilenme, canlanma ve prestij kazanma anlamları taşımakla birlikte beraberinde getirdiği çevresel yükler olumsuzluklar yaratabilmektedir. Çünkü kentsel dönüşüm uygulamalarında yapıların yıkılması sonucu ortaya çıkan yapısal atıklar kent için çözülmesi gereken yeni bir problem alanı doğurmaktadır. Kentsel dönüşüm uygulamalarının hızla devam ettiği bir il olan Kayseri için de yapısal atıklar bir problem alanıdır. Bu çalı̧̧ma kapsamında Kayseri’de kentsel dönüşüm etkinlikleri sonucu oluşan yapısal atıkların yönetimine ilişkin bir değerlendirme yapılmıştır. $\mathrm{Bu}$ amaçla, öncelikle dünyada ve Türkiye'de kentsel dönüşüm kavramı ele alınmış, kentsel dönüşüm alanlarındaki yapısal atık yönetim uygulamaları irdelenmiştir. Ardından Kayseri'de kentsel dönüşüm yapılan alanlar incelenmiştir. Kentsel dönüşüm uygulamaları sonucu oluşan yapısal atıkların yönetimine yönelik güncel durum değerlendirilmiş ve sorunlar saptanmış, çözüme yönelik öneriler geliştirilmiştir.
\end{abstract}

Anahtar Kelimeler: Kentsel dönüşüm, yapısal atık yönetimi, Kayseri

\section{C\&D WASTE AS A PROBLEM IN URBAN TRANSFORMATION PROJECTS AND RECOMMENDATIONS FOR SOLUTION: KAYSERI AS A CASE STUDY}

\begin{abstract}
Urban transformation projects implemented using urban renewal, improvement and regeneration methods have been given much attention in many parts of the world and in Turkey. The projects may mean renewing, reviving and gaining prestige for a city; however, the environmental burdens associated with it can create negative effects. This is because construction and demolition (C\&D) wastes that result from the destruction of buildings in urban transformation applications cause a new problem area which needs to be solved for the affected cities. C\&D waste is also a problem area for Kayseri, the city where urban transformation practices are at its peak. In this study, the evaluation of the management of the C\&D wastes resulting from urban transformation activities in Kayseri was made. With this aim, first of all, the concept of urban transformation in the world and in Turkey is discussed, and C\&D waste management practices in urban transformation areas are examined. Later, the areas where urban transformation was done are examined in Kayseri. Current situation on the management of C\&D wastes that have emerged as a result of these applications are evaluated, problems are identified and suggestions for solution are developed.
\end{abstract}

Keywords: Urban transformation, C\&D waste management, Kayseri

*Corresponding author / Sorumlu yazar. Tel.: +90 35243752 82; e-mail / e-posta: bsalgin@gmail.com 


\section{B. SALGIN, N. COŞGUN}

\section{GİRIŞ}

Sanayi Devrimi sonrası düzensiz yapılaşma nedeniyle oluşan sağlıksız çevrelerin ve İkinci Dünya Savaşı'nın yıkıcı etkileri ile zarar görmüş kentlerin yeniden yaşanabilir olmasını sağlamak amacıyla kentsel yenileme, iyileştirme ve canlandırma gibi uygulamalar gerçekleştirilmiştir. Benzer uygulamalar günümüzde "Kentsel Dönüşüm” adı altında gerçekleştirilmektedir.

Kentsel dönüşüm, "kapsamlı bir vizyon ve eylem olarak, bir alanın ekonomik, fiziksel, toplumsal ve çevresel koşullarının sürekli iyileştirilmesini sağlamaya çalışmak” olarak tanımlanabilir [1]. Kentsel dönüşüm, kentin;

- gecekondu alanlarında,

- sanayi alanlarının kent merkezlerini terk etmesi sonucu oluşan yıkıntı alanlarında,

- olası bir afet sonrasında en fazla zarar görmesi muhtemel olan alanlarında kamu ve birey yararına düzenleme yapılmasını hedeflemektedir [2].

Kentsel dönüşüm uygulamaları; niteliksiz/sağlıksız alanların yenilenmesi, işlevini kaybetmiş mekânlara yeni işlevler kazandırılması, doğal afetlerden etkilenecek yapıların dönüştürülmesi, kentsel alt yapının bu gelişim süreci içinde yenilenmesi [3] konularında yarar sağlamakla beraber; ciddi miktarda yapısal atıkların ortaya çıkması ile olumsuz sonuçlar da doğurmaktadır.

Yapı yıkımlarında ortaya çıkan her türlü yapı ürününden kaynaklanan yapısal atıklar miktarca ve kapladıkları alan açısından fazladır. Bu durum atık depolama alanlarını zorlamaktadır. Atıkların doğaya gelişigüzel biçimde bırakılması, yapısal atık yönetiminin uygun eylem adımları ile yürütülmemesi, tehlikeli atıkların denetim altına alınmaması, yapısal atıkların doğru değerlendirme seçenekleri ile değerlendirilememesi doğal/yapma çevre, canlı sağlı̆̆ 1 üzerinde olumsuz etkiler yaratmakta, parasal kayıplara neden olarak ülke ekonomisine zarar vermektedir [4]. Bu nedenle kentsel dönüşüm uygulamaları sonucu oluşan yapısal atıkların çevreye ve ülke ekonomisine yeni yükler getirmemesi için bu atıkların yönetilmesi önem taşımaktadır.

$\mathrm{Bu}$ amaçla çalışma kapsamında, hızla ve artarak devam eden kentsel dönüşüm uygulamaları ve bu uygulamalara bağlı olarak oluşan yapısal atıklar Kayseri örneğinde ele alınmıştır. Literatür taraması, saha araştırması ve çeşitli röportajlar içeren melez bir araştırma yöntemi benimsenen bu çalışmada sırasıyla; dünyadaki ve Türkiye'deki kentsel dönüşüm uygulamaları ve bu uygulamalardaki yapısal atık yönetim modelleri incelenmiştir. Kayseri özelindeki kentsel dönüşüm uygulamaları ele alınmış, yapısal atık yönetimine ilişkin güncel durum ortaya koyulmuştur. Sorunlar saptanmış, çözüme yönelik öneriler geliştirilmiştir.

\section{DÜNYADA VE TÜRKIYY'DE KENTSEL DÖNÜŞÜM UYGULAMALARI}

Kentsel dönüşüm uygulamaları ilk kez gelişmiş Batı ülkelerinde 19. yüzyılda sağlıksız kentsel yerleşme alanlarının toplumsal, ekonomik, politik, işlevsel ve mekânsal anlamda yeniden değerli konuma getirilmesi amacıyla başlamıştır [5, 6]. 1800'lerin ortalarından 1945'lere kadar kentlerdeki bozulmalara karşı en önemli müdahale biçimi kentsel yenilemedir (urban renewal) [7]. 1945'de İkinci Dünya Savaşı'nın sonunda Avrupa kentlerindeki yıkımlar nedeniyle kentlerin yeniden inşası (urban reconstruction) gündeme gelmiştir [5]. Tüm bir alanın tamamen yıkılıp yerine yeni bir şehir dokusu yapılmasını öneren bu politika 1960'larda tarihi yapıların korunması düşüncesinin yerleşmesiyle terk edilmiştir [8]. 1960-1970'lerin başında kentsel iyileştirme (urban improvement) ve kentsel yenileme çalışmaları gündeme gelmiştir [9]. 1980'li yıllarda kentsel yeniden yapılandırma (urban redevelopment) projeleri gündeme gelmiş, kentin boşalmış alanlarını ekonomik olarak canlandırmak amaçlanmıştır. 1990'lı yıllardan bugüne kadar yapılan en yaygın müdahale biçimi ise kentsel yenileme/kentsel canlandırma (urban regeneration) olmuştur [7].

Türkiye'de 1950'lerde sanayileşmeye bağlı olarak kırsal yerleşimlerden büyük kentlere denetimsiz bir şekilde göç yaşanması kaçak yapılaşma sorununu beraberinde getirmiştir. 1980'lere kadar hızla devam eden kentleşme, bu yıllarda gecekondu bölgelerinde dönüşüm kavramını gündeme taşımıştır. 1984 yılında 2981 sayılı "İmar ve Gecekondu Mevzuatına Aykırı Yapılara Uygulanacak Bazı İşlemler ve 6785 Sayılı İmar Kanununun Bir Maddesinin Değiştirilmesi Hakkındaki Kanun”, gecekondu bölgelerinin dönüşüm sürecinde önemli bir rol almıştır [7]. 1980'lerin sonlarına gelindiğinde kentsel dönüşüm projeleri belediyelerin gündemine alınmıştır. Dikmen Vadisi kentsel dönüşüm projesi, gecekondu bölgeleri için hazırlanan ilk kentsel dönüşüm projesi olmuştur [10].

Türkiye'de 1950'lerden bugüne yapıların yaygınlıkla betonarme yapım sistemleri ile üretilmesi [11] ve betonarme yapılar için yaklaşık 50 yıllık ömür biçilmesi [12] nedeniyle birçok yapının bu ömrü tamamlamış olduğu varsayılmakta, Türkiye'nin büyük bir bölümünün deprem riski taşıması ve geçmişten bugüne kaçak yapılaşmanın sürmesi, bazı yapıların da işlevsiz kalması nedenleriyle yerel yönetimler kentsel dönüşüm projelerine yönlenmiştir. Özellikle Temmuz 2005 tarihli ve 5393 sayılı Belediye Kanunu uyarınca büyükşehir 

KAYSERI ÖRNEĞI

belediyeleri, büyükşehir belediyesi sınırları içindeki ilçe ve ilk kademe belediyeleri ve il belediyeleri ile nüfusu 50.000'in üzerindeki belediyelere kentsel dönüşüm ve gelişim projeleri uygulayabilir yetkisinin verilmesiyle birlikte kentsel dönüşüm uygulamalarında hızlı bir artış olmuştur [7].

\subsection{Kentsel Dönüşüm Uygulamalarında Yapısal Atık Yönetimi}

Kentsel dönüşüm uygulamaları ile oluşan ve çeşitli olumsuz etkileri bulunan yapısal atıkların yönetimine ilişkin konular dünyada ve Türkiye'de, ülkelerin koşullarına göre çeşitli uygulamalarla ele alınmaktadır. Uygulamalar çeşitlilik göstermekle birlikte Avrupa Birliği'nin yaklaşımına göre atık yönetimi önleme/azaltma, yeniden kullanma, geri dönüştürme, geri kazanma ve yok etme olarak beş ana ilkeye dayanmaktadır. Buna göre yapısal atıkların yönetiminde öncelikli amaç atık oluşumunun önlenmesi, eğer önlenemiyorsa atığın azaltılmasıdır. Daha sonra atığın yeniden kullanımı, geri dönüşümü ve geri kazanımı amaçlanır. $\mathrm{Bu}$ yöntemlerden sonra kalan ya da bu yöntemlerin uygulanamadığı atıklara yapılabilecek en son işlem; düzenli depolama alanına gönderme veya yakarak yok etmedir [13].

Yapısal atıkların türü/miktarı, yapının ve kullanılan ürünlerin türüne, yapının yaşına bağlı olarak değişiklikler göstermektedir. Bununla birlikte kentsel dönüşümde yapılar -bazı yapı ürünlerinin ikinci el olarak yeniden kullanılabileceği durumlar dışında- tamamen atık duruma gelmektedir. $\mathrm{Bu}$ nedenle kentsel dönüşüm uygulamalarında yapıların yıkılma süreçlerinin planlı ve sistemli yapılması atıkların azaltılması açısından önemlidir [14].

Kentsel dönüşüm uygulamalarının yapısal atık yönetimi açısından başarılı olabilmesi yapı söküm/yıkım süreçlerinin sistematik bir şekilde yönetilmesine bağlıdır. Bu bağlamda -yol gösterici olması açısından- yapı söküm/yıkım süreçlerinde başarılı örnekler veren Hollanda ve Hong Kong'daki uygulamalar ile Avrupa Komisyonu 5. Çerçeve Programı kapsamında gerçekleştirilen IRMA (Integrated Decontamination and Rehabilitation of Buildings, Structures and Materials in Urban Renewal) başlıklı AR-GE projesi irdelenmiştir.

Hollanda; sınırlı bir kara parçası üzerinde olması nedeniyle yeni yapı yapacak ve atık depolayacak yeterli alanı bulunmaması [15], Hong Kong; artan nüfusun gereksinimlerini karşılayacak yeni alanlara gereksinim duyulması ve atık depolama için yeterli alan bulunmaması [16] nedenleriyle yapısal atık sorunu ile karşı karşıya kalmıştır. Belirtilen zorluklar bu ülkeleri söküm/yıkım süreçlerinde atık yönetimi konusunda mücadeleye itmiş ve başarılı uygulamalar gerçekleştirmişlerdir. IRMA projesi ise Avrupa ülkelerindeki kentsel yenileme süreçlerinde yapısal atıkların yönetimi konusunu ele aldığ için önemli bulunmuştur.

Hollanda'da yapıların yeniden işlevlendirilerek kullanılması ya da sökülen ürünlerin yeni yapılarda kullanılması oldukça yaygındır. Hükümet toplam yapısal atık miktarını azaltmak için 1 Nisan 1997'de yürürlüğe koyduğu zorunluluk ile kullanılabilir ve yakılabilir atıkların çöp sahalarına atılmalarını yasaklamıştır [15]. Bu yaklaşımla son yıllarda oluşan yapısal atıkların neredeyse \%95'i yeniden kullanılmakta, böylece atık oluşumunun önüne geçilmektedir [17].

Söküm/yıkım firmaları öncelikle binanın asbest gibi tehlikeli içerikte ürün barındırıp barındırmadığını denetlemekte, bulunması durumunda konunun uzmanı ekipler tarafindan sökülmesini ve alandan uzaklaştırılmasını sağlamaktadır. Ardından binaları;

- Ahşap döşemeli, ahşap çatılı, çatıları bitümlü örtü ya da kiremitle kaplanmış tuğla binalar,

- Betonarme iskeletli sistemler,

- Çelik iskelet sistemler olarak sınıflandırmaktadır.

Her üç sınıfta yer alan binalar için de öncelik yeniden kullanılacak ürünleri sökmek, geri dönüştürülecek ürünleri ayırmak, geri dönüşüm tesislerine göndermek, kalan atıkları ise geri kazanmak ya da düzenli depolama alanlarına göndermektir. Bununla birlikte binanın özelliğine göre söküm/yıkım teknikleri farklılık göstermektedir [17].

Hollanda'da Lansink Merdiveni adı verilen; önleme, parçaları yeniden kullanma, malzemeleri yeniden kullanma, yararlı uygulamalarla kullanma, enerji eldesi için yakma, yakma ve düzenli depolama adımlarından oluşan, yedi basamaklı atık yönetim hiyerarşisi geliştirilmiş̧ir. Bu sıralamada her zaman ilk seçenek sonraki seçenekten daha iyidir. Ancak bu yaklaşım katı bir hiyerarşi sunduğundan daha esnek bir model olarak Delft Merdiveni geliştirilmiştir. Bu hiyerarşide de benzer adımlar birbirini takip etmekle birlikte, ilk seçenek sonraki seçenekten daha iyidir yaklaşımı ortadan kalkmıştır. Ürünlerin yaşam döngüsü analizleri değerlendirilerek hangi seçeneğin daha yararlı olabileceğine karar verilmektedir [17].

Hong Kong, 1993 ile 2004 yılı arasında yapı sektörü etkinliklerinin iki kat büyümesi ve bu sektörden kaynaklanan yapısal atıklar nedeniyle önemli bir katı atık üreticisi durumuna gelmiştir [16]. 2006 y1lında "Kirleten Öder" ilkesi ile hükümet tarafindan getirilen Atık Ücretlendirme Planı (Waste Charging Scheme) ve atıkları sınıflandırma yöntemi ile yapısal atık yönetiminde önemli bir yol kat etmiştir. Atık depolama sahalarına sınıflandırmadan, karışık bir şekilde gönderilen atıklar için sınıflandırılmış olarak gönderilen atıklara oranla ton 


\section{B. SALGIN, N. COŞGUN}

başına yaklaşık 5 kat daha yüksek ücret belirlenmiştir [18, 19]. Bu durum yıkımı gerçekleştiren firmaları seçici yıkıma yönelme ve depolama sahalarına daha az atık gönderme konusunda teşvik etmektedir.

Avrupa Komisyonu 5. Çerçeve Programı kapsamındaki IRMA projesi 17 ülkenin katılımı ile gerçekleştirilmiş ve 'kentsel yenilemede Şehir Konsepti (City Concept) nasıl olmalıdır?' sorusunun cevabını aramaya odaklanmıştır [20]. Bu amaçla öncelikle kentsel yenileme süreçlerindeki ana sorunlar ortaya koyulmuş, bir yönetim modeli geliştirilmiştir. Bu model çevrenin ve insanların korunması için binalar üzerinde yoğunlaşmakta, yıkım süreçleri yönetimini;

- Binaların kullanıcıları için riski en aza indirmek,

- Yıkım işçilerinin sağlığını ve güvenliğini korumak,

- Atıkları azaltmak,

- (Mümkünse) binaları ve kaynakları korumak hedefleri doğrultusunda ele almaktadır [20].

Kentsel yenileme süreci için geliştirilen ve Şehir Konsepti olarak tanımlanan kavramsal modelde (Şekil 1) kentsel yenileme yapılacak bölge için;

- Yeni amaçlar için kullanılamayacak durumda olan binaların ve alt yapının sökülmesi/yıkılması ve yeniden kullanımın/geri dönüşümün -en yüksek düzeyde- sağlanması,

- Var olan binaların ve alt yapının yeniden kullanımının sağlanması için iyileştirme yapılması olarak belirtilen iki tamamlayıcı yaklaşım bulunmaktadır.

Buna göre kentsel yenileme süreçlerinde uygulanacak ve yönetim planına eklenecek yapısal atık yönetim adımları;

- Binalardaki tehlikeli içeriklerin belirlenmesi ve sınıflandırılması,

- Y1kım sırasındaki zararlı salımların önlenmesi,

- Binanın taşıyıcı sisteminin yaşam süresinin uzatılması,

- Var olan binanın iyileştirilerek yeniden kullanılması,

- Yapısal atıklarının geri dönüştürülmesi,

- Geri dönüştürülecek yapısal atıklar için ayırma ve kırma işlemlerinin kentsel yenileme bölgesindeki boş alanlarda yapılması, sadece tehlikeli içerikteki ve geri dönüştürülemeyen atıkların saha dışındaki depolama alanlarına gönderilmesi,

- Bütüncül ya da seçici yıkımla yapısal atıkların geri kazanılması olarak belirlenmiştir [21].

Modelin (özellikle söküm/yıkım uzmanları/firmaları tarafindan) kullanılması ile kentsel yenileme çalışmalarında oluşacak yapısal atıkların azalacağı düşünülmektedir.

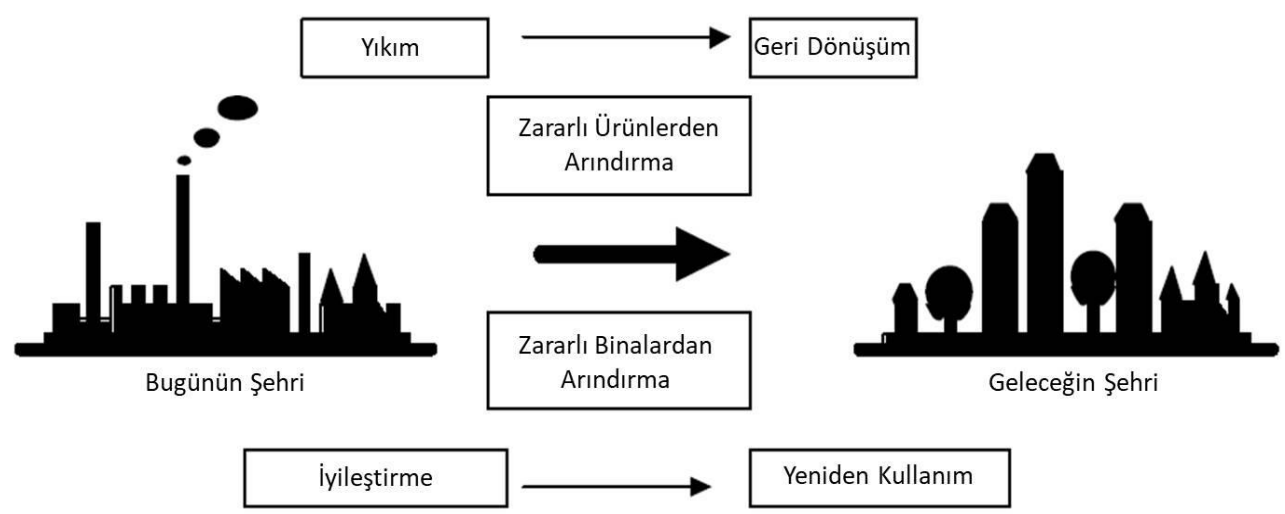

Şekil 1. Şehir Konsepti için Kavramsal Model [20]

Farklı ülkelerde farklı nedenlerle yürütülen kentsel dönüşüm uygulamaları ve yapı yıkım süreçleri Türkiye'de de hizla devam etmektedir. Acar'a [22] göre kentsel dönüşüm sürecinde Türkiye genelinde 6,5 milyon konutun yıkılıp yeniden yapılmasının amaçlandığı belirtilmektedir. Buna göre oluşacak yapısal atık miktarının da yıllık 45 milyon ton olacağı hesaplanmıştır [22]. Bu noktada oluşacak bu atıkların nasıl toplanacağı, hangi yöntemlerle değerlendirilebileceği, değerlendirilemeyecek olanların hangi alanlara gönderileceği vb. konuları önem taşımaktadır. Türkiye'de yıkım süreçleri açısından mevcut durum incelendiğinde;

- Yıkımların; yapı yıkım firmaları ve ikinci el malzeme sağlayıcıları tarafından yapıldığı,

- Yapının taşıyıcı sisteminin yıkımı yapılmadan önce ikinci el olarak satılabilecek yapı ürünlerinin söküldüğ̈̈,

- Yapının tekrar kullanılamayacak bölümlerinin yıkım firmaları tarafından moloz haline getirilerek atık döküm yerlerine veya dolgu amaçlı boş arazilere döküldüğü söylenebilir. 

KAYSERI ÖRNEĞ $\dot{I}$

Kentsel dönüşüm etkinlikleri sonucunda ortaya çıkacak büyük miktardaki yapısal atıkların yönetimine ilişkin Türkiye koşulları için geliştirilmiş, zorunluluklar çerçevesinde tanımlanmış bir yönetim modeli olmamakla birlikte yapısal atık yönetimi konularını ilgilendiren çeşitli zorunluluklar bulunmaktadır. Başlıca zorunluluklar; Kanunlar:

- 2872 sayılı Çevre Kanunu,

- 5216 sayılı Büyükşehir Belediyesi Kanunu,

- 3194 sayılı İmar Kanunu,

- 5326 say1lı Kabahatler Kanunu,

Yönetmelikler:

- 18.03.2004 tarihli ve 25406 sayılı Resmi Gazetede yayınlanarak yürürlüğe giren "Hafriyat Toprağı, İnşaat ve Yıkıntı Atıklarının Kontrolü Yönetmeliği”,

- 23 Ocak 2010 tarihli ve 27471 sayılı Resmi Gazetede yayınlanarak yürürlüğe giren "Madencilik Faaliyetleri ile Bozulan Arazilerin Doğaya Yeniden Kazandırılması Yönetmeliği”,

- 26 Mart 2010 tarihli ve 27533 sayılı Resmi Gazetede yayınlanarak yürürlüğe giren “Atıkların Düzenli Depolanmasına Dair Yönetmelik",

- 30 Eylül 2010 tarihli ve 27715 sayılı Resmi Gazetede yayınlanarak yürürlüğe giren “Orman Kanununun 16 ncı Maddesinin Uygulama Yönetmeliği” olarak özetlenebilir [23].

$\mathrm{Bu}$ zorunluluklar içinde yapısal atıkları en kapsamlı biçimde ele alan "Hafriyat Toprağı, İnşaat ve Yıkıntı Atıklarının Kontrolü Yönetmeliği’”ne göre atıkların toplanması ve yönetilmesi sorumluluğu belediyelere verilmiştir. Belediyeler;

- Yapısal atıklarının toplanması, geçici biriktirilmesi, taşınması, geri kazanılması ve yok edilmesi ile ilgili yönetim planı hazırlamakla,

- Yapısal atık geri kazanım tesislerinin sahaları ile depolama sahalarını belirlemek, kurmak/kurdurtmak ve işletmek/işlettirmekle,

- Depolama sahası yerinin seçimi, yapılması veya işletilmesi sırasında çevre ve insan sağlığını olumsuz etkilemeyecek şekilde gerekli tedbirleri almak veya aldırtmakla,

- Bu planlar ile tedbirleri gerçekleştirmek ve bunlara uymayanlara cezai yaptırım uygulamakla yükümlüdür [24].

Yönetmeliğe göre, yıkımı gerçekleştiren firmalar gerekli ruhsat ve belgeleri bulundurmak zorundadır. Ayrıca yapısal atıkların taşınması ve boşaltılması işleri için izin alınması gerekmektedir. Böylece yapısal atıkların yıkım sahasından döküm sahasına kadar ulaşımı sağlanarak kayıt altına alınabilmektedir [25].

Belirtilen zorunluluklara ek olarak, T.C. Çevre ve Şehircilik Bakanlığı, Nisan 2017 'de "Yıkım İşlemleri ile Hafriyat Toprağı, İnşaat ve Yıkıntı Atıklarının Kontrolü Yönetmeliği” taslağını görüşe açmıştır. 2004 yılında yürürlüğe giren "Hafriyat Toprağı, İnşaat ve Yıkıntı Atıklarının Kontrolü Yönetmeliği”nden sonra bu taslağın hazırlanma amacının -özellikle kentsel dönüşüm uygulamaları ile- artan yıkım etkinlikleri nedeniyle oluşan atıkları yönetmek olduğu düşünülmektedir. 2004 tarihli yönetmeliğe ek olarak taslakta gündeme alınan en önemli konu seçici yıkım ile ilgilidir. Seçici yıkıma 2004 tarihli yönetmelikte sadece tanım olarak yer verilirken, 2017 tarihli taslakta ayrıntılarıyla ele alınmıştır. "Yıkıntı atıklarının yüksek oranda geri dönüşümünü sağlamak amacıyla, yıkım öncesinde ve sırasında tehlikeli atıkların ayıklanmasını ve diğer malzemenin tekrar kullanılabilmesini ve geri dönüşümünü temin etmek üzere, yıkımın, kontrollü olarak ve malzemenin niteliğine göre aşamalı sökülerek yapılmasını” ifade eden seçici yıkım bu taslak ile zorunlu hale gelmiştir. Seçici yıkım uygulaması içeren yıkım planı hazırlamak/hazırlatmak ve uygulamak konularından ise yüklenici firma sorumlu tutulmuştur [26]. Sırasıyla;- “Asbest ve diğer tehlikeli atıkların kaldırılması,

- Çatı, kapı ve pencerelerin kaldırılması,

- Lavabo ve benzeri malzemenin kaldırılması,

- Metal malzemenin kaldırılması,

- Ahşap malzemenin kaldırılması,

- Alçı ürünlerinin kaldırılması,

- Tuğla ve diğer duvar malzemesinin kaldırılması,

- Yol ve diğer asfalt kaplı alanlarda asfalt tabakalarının kazınması veya kaldırılması,

- Yollar ve diğer alanlarda asfalt, beton ve parke kaplama tabakaları altında yer alan kırılmış ve/veya elenmiş granüler malzemelerin kaldırılması" aşamalarını kapsayan seçici yıkımlarda dikkate değer en önemli nokta asbest gibi tehlikeli atıkların sökümü ile ilgilidir [26].

2004 tarihli yönetmelikte asbest içeren ürünlerin "Asbestle Çalışmalarda Sağlık ve Güvenlik Önlemleri Hakkında Yönetmelik" esaslarına uyularak sökülmesi gerektiği belirtilirken, taslakta "Asbest Sökümü ile İlgili Eğitim Programlarına İlişkin Tebliğ” hükümlerine de uyulması gerektiği belirtilmiştir.

Türkiye'de 2008 yılından itibaren asbest kullanımı denetim altına alınmış, Aralık 2010 tarihinde Bakanlar Kurulu kararıyla çıkarılan yönetmelikle asbest kullanımı yasaklanmış olsa da bu tarihe kadar yapılan kamu 


\section{B. SALGIN, N. COŞGUN}

yapısı, konut, işyeri ve benzeri birçok yapıda asbestli ürünler bulunmaktadır. Bu ürünlerin denetimsiz sökümü sırasında havada asılı asbest liflerinin solunum yoluyla akciğerlere ulaşması ve liflerin akciğer dokusunda birikmesi zamanla asbestten kaynaklanan çeşitli sağlık sorunlarına neden olmaktadır [27]. Bu nedenle kentsel dönüşüm süreçlerindeki yıkımlarda asbest başta olmak üzere tehlikeli atıkların sökümünün de denetimli bir şekilde ve zorunluluklara uygun olarak yapılması önemlidir.

\section{KAYSERI'DE KENTSEL DÖNÜŞÜM UYGULAMALARI VE YAPISAL ATIK SORUNU}

Kayseri'de; Büyükşehir, Melikgazi, Kocasinan ve Talas Belediyesi tarafından, kendi sınırları içinde çeşitli bölgelerde kentsel dönüşüm projeleri hazırlatılmış, projeler etaplanarak bir bölümünün uygulanmasına başlanmıştır. Kentsel dönüşüm alanları seçilirken;

- yararlı ömrünü tamamlamış yapıların yenilenmesi,

- afet riski altındaki yapıların ortadan kaldırılması,

- izinsiz yapılaşmanın yok edilmesi ölçütleri dikkate alınmıştır.

“6306 sayılı Afet Riski Altındaki Alanların Dönüştürülmesi Hakkında Kanun” uyarınca Kayseri ili sınırları içerisinde bazı mahallelerde riskli alanlar saptanmış ve bu mahallelerde kentsel dönüşüm çalışmaları yapılmaya başlanmıştır. Kanunda;

- Riskli alan; zemin yapısı veya üzerindeki yapılaşma sebebiyle can ve mal kaybına yol açma riski taşıyan, Bakanlık veya İdare tarafından Afet ve Acil Durum Yönetimi Başkanlığının görüşü de alınarak belirlenen ve Bakanlığın teklifi üzerine Bakanlar Kurulunca kararlaştırılan alan,

- Riskli yapı ise; riskli alan içinde veya dışında olup ekonomik ömrünü tamamlamış olan ya da yıkılma veya ağır hasar görme riski taşıdığı bilimsel ve teknik verilere dayanılarak belirlenen yapı veya yapılar olarak tanımlanmıştır.

\subsection{Kayseri’de Kentsel Dönüşüm Uygulamaları}

2016 y1lı verilerine göre; Kocasinan'da 92, Melikgazi'de 31, Talas'ta 14 ve diğer ilçelerde 7 adet yapı 6306 sayılı kanun kapsamında riskli yapı olarak ilan edilmiş olup, toplamda 144 yapı / 510 bağımsız bölüm kentsel dönüşüm kapsamına alınmıştır [28].

\subsubsection{Kayseri Büyükşehir Belediyesi Kentsel Dönüşüm Uygulamaları}

Kocasinan Belediyesi sınırları içinde olmakla beraber Sahabiye ve Fatih Mahalleleri'nin kentsel dönüşüm çalışmaları Kayseri Büyükşehir Belediyesi’nin bünyesinde gerçekleştirilmektedir.

Sahabiye Mahallesi'nde kentsel dönüşüm çalışmaları, Resmi Gazete'de yayımlanan 27.12.2016 tarih ve 2016/9706 sayılı kararname doğrultusunda yapılmaktadır [29]. Yapılardaki eskimeler/yıpranmalar ve buna bağlı olarak oluşan alt yapı sorunları, deprem dayanımının azalması nedenleriyle dönüşüm çalışmalarının başlatıldığı belirtilmiştir.

Sahabiye Mahallesi'nde Kayseri Koruma Kurulu'nun belirlediği yapılar haricindeki tüm yapıların yıkılması planlanmaktadır (Şekil 2 ve 3). İlk etapta deprem riski taşıyan yapıların yoğun olduğu Ahmet Paşa Caddesi ile Açık Sokak arasında kalan alandan başlanarak çoğunluğu 3-5 katlı yapılardan oluşan eski/yeni tüm yapıların yıkılması planlanmıştır [30]. Sahabiye ve Fatih mahallerinde toplam kentsel dönüşüm alanı $62.000 \mathrm{~m}^{2}$ olarak belirlenmiştir [29].

\subsubsection{Melikgazi Belediyesi Kentsel Dönüşüm Uygulamaları}

Melikgazi Belediyesi bünyesinde Küçükali, Anbar, Kazımkarabekir ve Karacaoğlu Mahalleleri’nde kentsel dönüşüm çalışmaları yapılmaktadır. Yapılardaki eskimeler/yıpranmalar ve izinsiz yapılaşmayı ortadan kaldırmak için dönüşüm çalışmalarının başlatıldığı belirtilmiştir.

Küçükali Mahallesi Resmi Gazete'de yayımlanan 16.10.2015 tarih ve 2015/8201 sayılı kararname ile riskli alan olarak belirlenmiştir. Mahalledeki kentsel dönüşüm alanı $129.300 \mathrm{~m}^{2}$ 'dir (Şekil 4) [32]. Y1kılan tek katlı yapıların yerine 12-15 katlı yapılar yapılacaktır [33].

Anbar Mahallesi Resmi Gazete'de yayımlanan 16.10.2015 tarih ve 2015/8200 sayılı kararname ile riskli alan olarak belirlenmiştir. Mahalledeki kentsel dönüşüm alanı 43.300 m²'dir (Şekil 5) [35]. Yıkılan tek katlı yapıların yerine 7-10 katlı yapılar yapılacaktır [33]. 


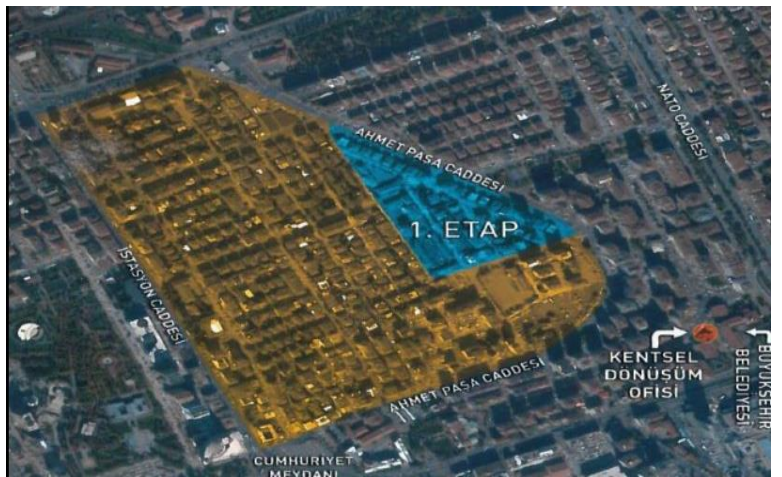

Şekil 2. Sahabiye Mahallesi kentsel dönüşüm alanı sinırlar1 [30]

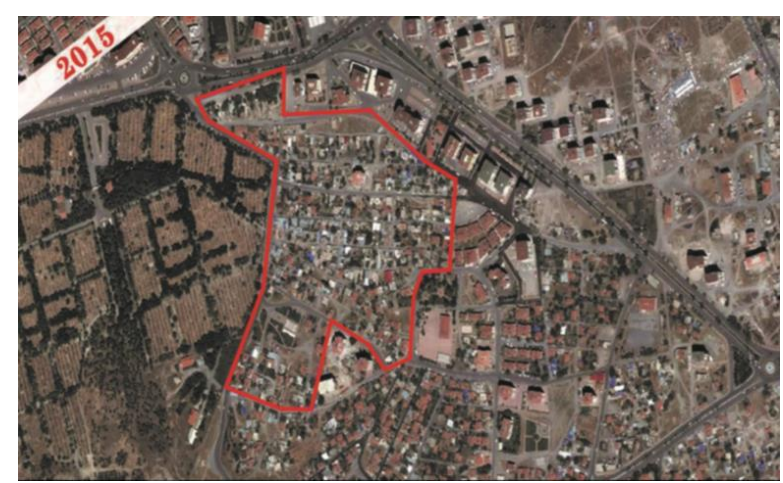

Şekil 4. Küçükali Mahallesi kentsel dönüşüm alanı sinırlar1 [34]

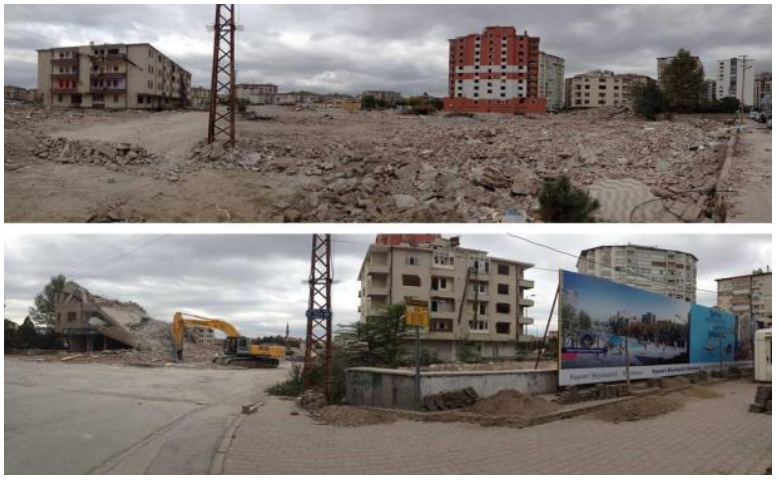

Şekil 3. Sahabiye Mahallesi'ndeki kentsel dönüşüm alanlarında yıkım çalışmaları [31]

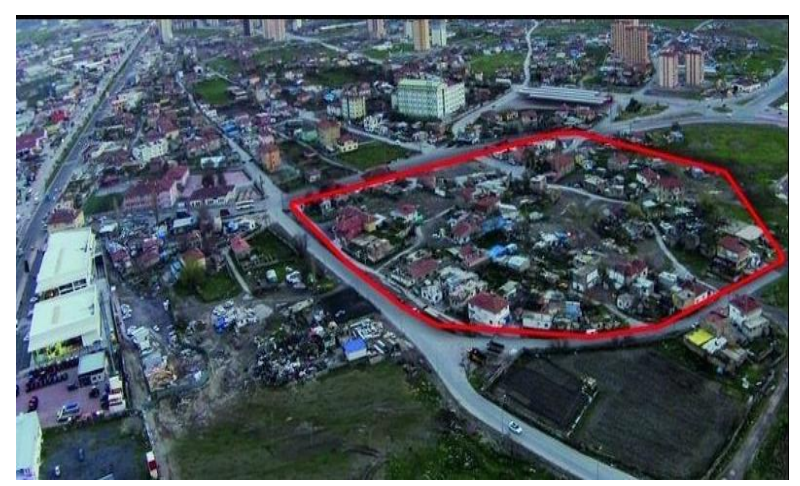

Şekil 5. Anbar Mahallesi kentsel dönüşüm alanı sinırlar1 [34]

Kazımkarabekir Mahallesi Resmi Gazete'de yayımlanan 27.12.2016 tarih ve 2016/9708 sayılı kararname ile riskli alan olarak belirlenmiştir. Mahalledeki kentsel dönüşüm alanı 290.800 m²'dir (Şekil 6) [36]. Yıkılan tek katlı yapıların yerine 15 katlı yapılar yapılacaktır [33].

Karacaoğlu Mahallesi'nde izinsiz yapılaşmanın ortadan kaldırılması amacıyla kentsel dönüşüm yapılacaktır. Proje uygulanacak alan/alanlar için çalışmalar devam etmektedir (Şekil 7) [33].

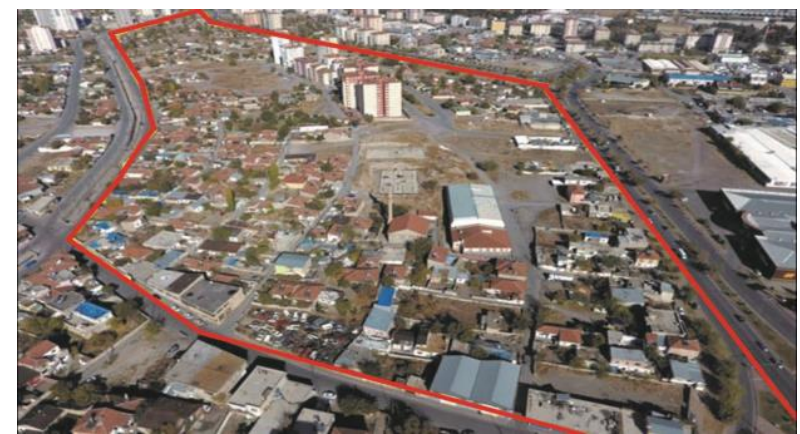

Şekil 6. Kazımkarabekir Mahallesi kentsel dönüşüm alanı sinırları [34]

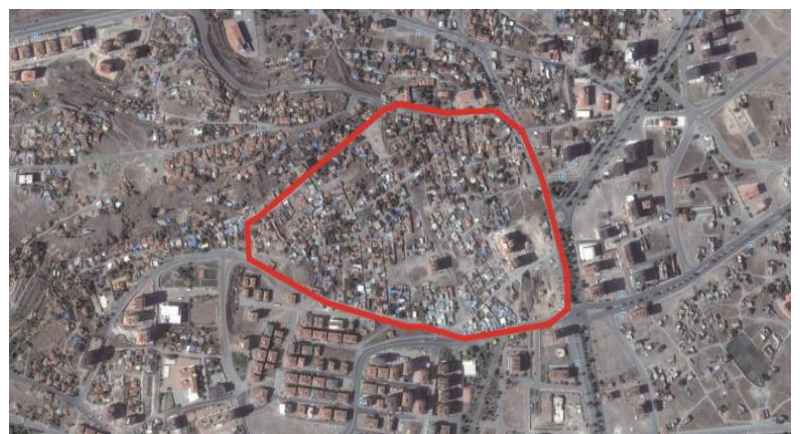

Şekil 7. Karacaoğlu Mahallesi kentsel dönüşüm alanı sinırları [34]

\subsubsection{Kocasinan Belediyesi Kentsel Dönüşüm Uygulamaları}

Kocasinan Belediyesi bünyesinde Yunusemre, Alsancak, Seyrani, Ziyagökalp, Yenidoğan, Ahievran, Argıncık, Kuşçu ve Cırkalan Mahalleleri’nde yapılardaki eskimeler/yıpranmalar nedeniyle kentsel dönüşüm çalışmaları yapılmaktadır (Şekil 8). Bu çalışmaların bir kısmı belediye tarafından, bir kısmı ise ihale yoluyla yükleniciler tarafindan yapılmaktadir [37]. 


\section{B. SALGIN, N. COŞGUN}

Yunusemre, Alsancak ve Seyrani Mahalleleri Resmi Gazete'de yayımlanan 15.06.2015 tarih ve 2015/7859 sayılı kararname ile riskli alan olarak belirlenmiştir. Kentsel dönüşüm alanları; Yunusemre Mahallesi'nde $125.300 \mathrm{~m}^{2}$, Alsancak Mahallesi'nde $69.000 \mathrm{~m}^{2}$ ve Seyrani Mahallesi'nde ise $441.800 \mathrm{~m}^{2}$ 'dir [39]. Y1k1lan tek katlı yapıların yerine 14 katlı yapılar yapılacaktır [37].

Ziyagökalp ve Yenidoğan Mahalleleri Resmi Gazete'de yayımlanan 26.09.2016 tarih ve 2016/9286 say1l kararname ile kentsel dönüşüm ve gelişim proje alanı olarak belirlenmiştir. Ziyagökalp Mahallesi'nde kentsel dönüşüm alanı yaklaşık $205.000 \mathrm{~m}^{2}$ 'dir [40]. Yıkılan tek katlı yapıların yerine 14 katlı yapılar yapılacaktır [37].

Ahievran Mahallesi Resmi Gazete'de yayımlanan 24.11.2014 tarih ve 2014/7031 sayıl kararname ile riskli alan olarak belirlenmiştir. Mahallede kentsel dönüşüm alanı $589.400 \mathrm{~m}^{2}$ dir [41]. Yıkılan tek katlı yapıların yerine 14 katlı yapılar yapılacaktır [37].

Argıncık, Kuşçu ve Cırkalan Mahalleleri'nden; Kuşçu Mahallesi Resmi Gazete'de yayımlanan 27.12.2016 tarih ve 2016/9725 sayılı kararname ile [42], Cirkalan Mahallesi Resmi Gazete'de yayımlanan 26.09.2016 tarih ve 2016/9285 sayılı kararname ile kentsel dönüşüm ve gelişim proje alanı olarak belirlenmiştir [43]. Kentsel dönüşüm alanları; Argıncık Mahallesi’nde yaklaşık $69.000 \mathrm{~m}^{2}$, Kuşçu Mahallesi'nde $230.000 \mathrm{~m}^{2}$, Cırkalan Mahallesi'nde $2.465 .000 \mathrm{~m}^{2}$ 'dir [37, 42, 43]. Yıkılacak tek katlı yapıların yerine kaç katlı yapılar yapılacağı henüz kesinleşmemiştir [37].

\subsubsection{Talas Belediyesi Kentsel Dönüşüm Uygulamaları}

Talas Belediyesi bünyesinde Resmi Gazete'de yayımlanan 26.09.2016 tarih ve 2016/9284 sayılı kararname doğrultusunda; Harman, Mevlana ve Başakpınar Yıldıztepe Mahalleleri'nde bulunan bazı alanlar kentsel dönüşüm ve gelişim proje alanı olarak belirlenmiştir (Şekil 9) [44]. Belediyenin ilgili birimleri ile görüşmeler yapılmasına rağmen, çalışmaların ne düzeyde olduğuna ya da içeriğine ilişkin bir bilgi alınamamıştır.

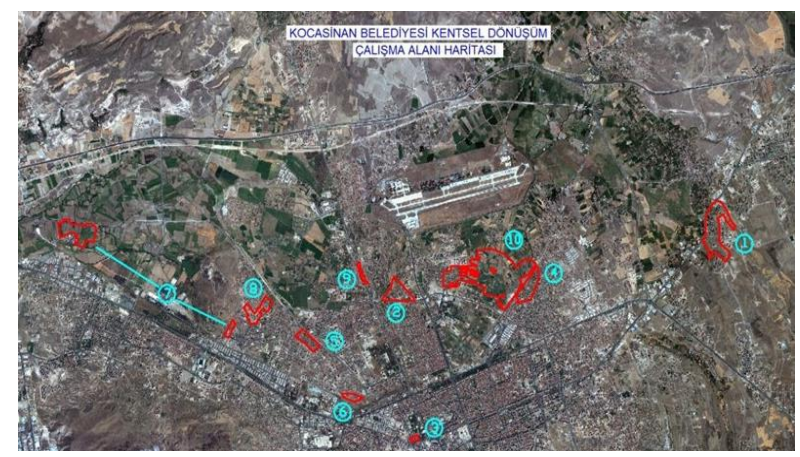

Şekil 8. Kocasinan Belediyesi'nde kentsel dönüşüm alanlar1 [38]
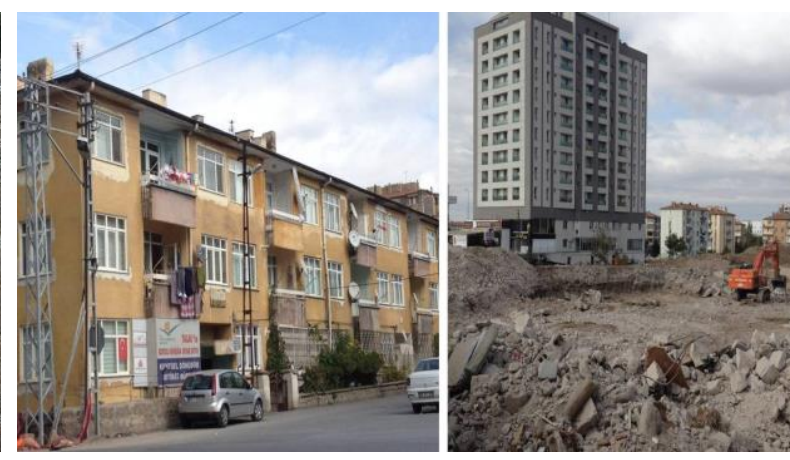

Şekil 9. Talas Belediyesi kentsel dönüşüm uygulamalar1 [31]

\subsection{Kayseri'de Kentsel Dönüşüm Uygulamaları Sonucu Oluşan Yapısal Atıkların Yönetiminde Güncel Durum ve Sorunlar}

Yapısal atıkların durumu açısından Kayseri'de güncel durum incelendiğinde; Büyükşehir, Melikgazi, Kocasinan ve Talas Belediyeleri ile yapılan görüşmeler sonucunda edinilen bilgiye göre yapısal atıkların yönetimi ile ilgili özel bir çalışma yapılmadığı görülmektedir.

Büyükşehir ve Melikgazi Belediyeleri 2006-2015 yılları arasında Küçükali Mahallesi'nde belirlenmiş bir alanı hafriyat döküm alanı olarak kullanmıştır. Ancak yıllar içinde döküm alanının dolması nedeniyle bu alan kapatılmış ve belediye eliyle düzenlenerek hobi bahçesi olarak hizmete açılmıştır. Güncel olarak Melikgazi Belediyesi sınırları içinde kentsel dönüşüm alanlarındaki yıkılacak yapılarda öncelikle ikinci el ürün pazarında değerlendirmek üzere sökümlerin yapıldığı -bu konuda bir yaptırım olmamakla birlikte- Kentsel Dönüşüm Müdürlüğü Yıkım Departmanı çalışanlarının mal sahiplerini ve yüklenicileri motive ettikleri anlaşılmaktadır. Yıkılacak yapılardan sökülen vitrifiye ürünleri, kiremitler, kapı/pencere doğramaları ve ahşap döşemeler Konaklar mevkiinde bulunan ikinci el ürün satış pazarına gönderilmekte ve yeniden kullanıma sunulmaktadır (Şekil 10). Kalan yapının yıkım işleminin tamamlanmasıyla birlikte dolgu olarak kullanılacak nitelikteki atıklar Yeşilyurt ve Mimarsinan Şirintepe Mahalleleri'ne gönderilmekte, buradaki yol yapım işlerinde dolgu olarak kullanılmaktadır. Dolgu için kullanılamayacak nitelikteki atıklar ise -şehir merkezine $21 \mathrm{~km}$ uzaklıkta- Molu Köyü yakınlarındaki katı atık depolama alanına gönderilmektedir [33]. 

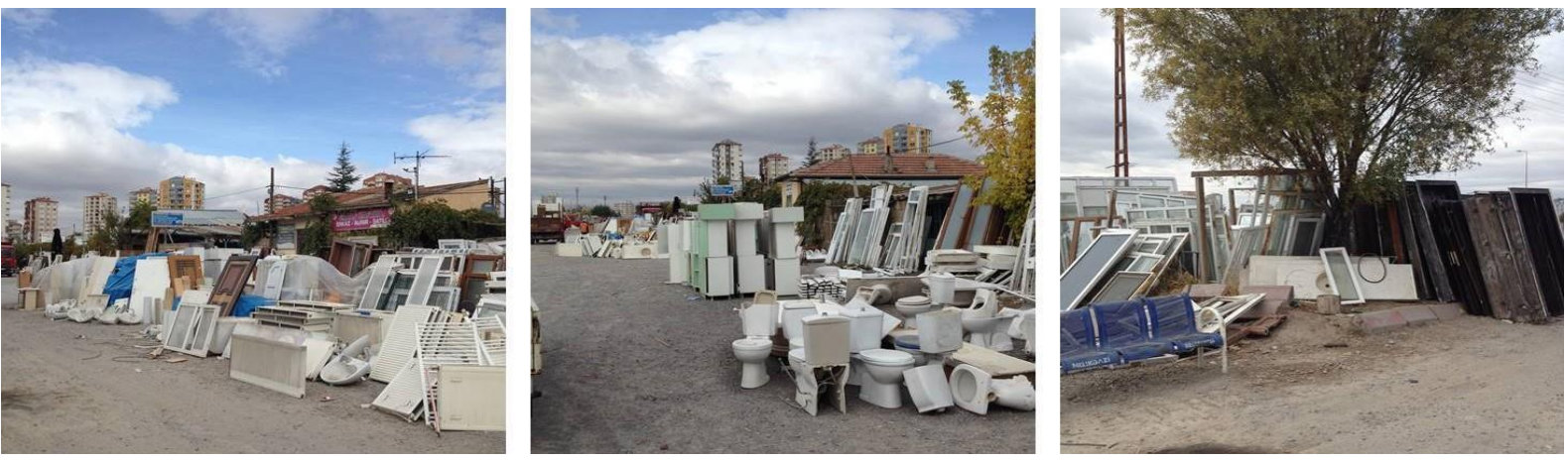

Şekil 10. İkinci El Ürün Satış Pazarı [31]

Kocasinan Belediyesi sınırlarında oluşan yapısal atıklar Erkilet Bülbül Pınarı mevkiindeki hafriyat döküm alanına ve Talas Belediyesi sınılarında oluşan yapısal atıklar ise Başakpınar Komando Tugayı yakınlarındaki eski bims ocağında bulunan hafriyat döküm alanına dökülmektedir. Bu atıklar da tıpkı Melikgazi Belediyesi’nin uygulamasında olduğu gibi gerekli görüldüğü takdirde belediyelerin dolgu ve stabilize işlerinde kullanılmaktadır.

Yapısal atıkları belediyelerin belirttiği alanlar dışındaki alanlara kaçak döküm yapanlar hakkında 5326 sayılı Kabahatler Kanunu'nun 41.4 maddesi gereğince cezai yaptırım uygulanmaktadır. Belediyelerin ilgili birimlerinden yetkililerle yapılan görüşmeler sonunda anlaşılmaktadır ki; kentsel dönüşümde büyük yıkımlar sonucu çıkan yapısal atıkların belirtilen alanlar dışına kaçak olarak dökülmesi para cezası uygulamalarıyla önlenmeye çalışılmaktadır. Bununla birlikte özellikle konut sahiplerinin özel mülklerinde yaptırdıkları onarımlar/yenilemeler sonucunda çıkan atıkların kaçak dökümünün önünde geçilmekte zorlanıldığı bilgisine ulaşılmıştır. Kaçak dökümlerin en önemli nedeninin döküm/depolama alanlarının şehir merkezine uzak olmalarından kaynaklandığı düşünülmektedir. Kayseri ili kentsel dönüşüm alanları ve yapısal atık yönetimi açısından güncel durum bilgileri Tablo 1'de sunulmuştur.

Tablo1. Kayseri İli kentsel dönüşüm alanları ve yapısal atık yönetimi açısından güncel durum

\begin{tabular}{|c|c|c|c|c|c|c|}
\hline İlçe & $\begin{array}{c}\text { Kentsel Dönüşümm } \\
\text { Yapılan } \\
\text { Mahalleler }\end{array}$ & $\begin{array}{l}\text { Kentsel Dönüşüm } \\
\text { Gerekçesi }\end{array}$ & $\begin{array}{c}\text { Toplam } \\
\text { Çalışsma Alanı } \\
\left(\mathbf{m}^{2}\right) \text { (yaklaşık) }\end{array}$ & $\begin{array}{c}\text { Tahmini Attk } \\
\text { Miktarı }\end{array}$ & $\begin{array}{c}\text { Yapısal } \\
\text { Atık } \\
\text { Döküm } \\
\text { Alanı } \\
\end{array}$ & $\begin{array}{c}\text { Yapısal } \\
\text { Atık } \\
\text { Yönetim } \\
\text { Planı } \\
\end{array}$ \\
\hline 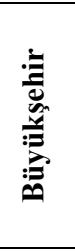 & $\begin{array}{l}\text { - Sahabiye } \\
\text { - Fatih }\end{array}$ & $\begin{array}{l}\text { - Yararlı ömrünü } \\
\text { tamamlamış } \\
\text { yapıların } \\
\text { yenilenmesi } \\
\text { • Afet riski } \\
\text { altındaki yapıların } \\
\text { ortadan kaldırılmas1 }\end{array}$ & $62.000 \mathrm{~m}^{2}$ & Hesaplanmamış & Var & Yok \\
\hline 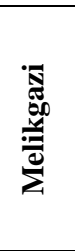 & $\begin{array}{l}\text { - Küçükali } \\
\text { - Anbar } \\
\text { - Kazımkarabekir } \\
\text { - Karacaoğlu }\end{array}$ & $\begin{array}{l}\text { • Yararlı ömrünü } \\
\text { tamamlamış } \\
\text { yapıların } \\
\text { yenilenmesi } \\
\text { • İzinsiz } \\
\text { yapilaşmayı yok } \\
\text { etmek }\end{array}$ & $463.400 \mathrm{~m}^{2}$ & Hesaplanmamış & Var & Yok \\
\hline 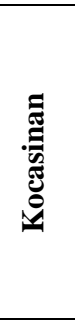 & $\begin{array}{l}\text { - Yunusemre } \\
\text { - Alsancak } \\
\text { - Seyrani } \\
\text { - Ziyagökalp } \\
\text { - Yenidoğan } \\
\text { - Ahievran } \\
\text { - Argincık } \\
\text { - Kuşçu } \\
\text { - Cirkalan }\end{array}$ & $\begin{array}{l}\text { - Yararlı ömrünü } \\
\text { tamamlamış } \\
\text { yapıların } \\
\text { yenilenmesi }\end{array}$ & $4.194 .500 \mathrm{~m}^{2}$ & Hesaplanmamış & Var & Yok \\
\hline$\frac{\mathscr{n}}{\pi}$ & $\begin{array}{l}\text { - Harman } \\
\text { - Mevlana } \\
\text { - Başakpinar } \\
\text { - Yildiztepe }\end{array}$ & - Bilgi Alınamadi & Bilgi Alınamadı & Hesaplanmamış & Var & Yok \\
\hline
\end{tabular}




\section{B. SALGIN, N. COŞGUN}

\section{SONUÇLAR}

Kentlerin gelişmesine ve değişmesine bağlı olarak; yapıların eskimesi, işlevsiz hale gelmeleri, kullanılmayan yapıların oluşturduğu sosyal problemler nedeniyle kentsel dönüşüm çalışmaları zorunlu hale gelebilmektedir. Ancak kentsel dönüşüm alanlarında belirlenen yapıların yıkılması sonucu büyük miktarda yapısal atık oluşumu çözülmesi gereken bir sorun olarak karşımıza çıkmaktadır.

- Belirtilen uygulamalarının yoğun olarak yaşandığı bir kent olan Kayseri için yapısal atık yönetimi açısından güncel durum incelendiğinde; kentsel dönüşüm uygulamalarında sadece projelendirme ve projeleri hayata geçirme düzeyinde çalışmaların yapılması ancak oluşacak büyük miktarlardaki yapısal atıkların yönetimine ilişkin bir plan olmaması,

- Kentsel dönüşümün öncelikli gerekçesi olarak yapılardaki eskime ve yıpranmaların gösterilmesi (Tablo 1), oysa atık yönetimindeki ilk hedefin önleme/azaltma olduğu bilgisinden hareketle eskimeler sonucunda yapıları doğrudan yıkmak yerine yeniden kullanım için bir çaba olması gerektiği ancak Kayseri için yeniden kullanımı özendirici çalışmaların sınırlı olması/olmaması kentsel dönüşüm uygulamalarının zayıf noktası olarak düşünülmektedir.

Bu çalışmaların plansız yapılmasıyla ortaya çıkacak atık miktarları ve uzun vadede çevrede yaratacağı olumsuz etkiler düşünüldüğünde gerek çalışma alanı olan Kayseri için, gerekse Türkiye'deki diğer iller için yapısal atık yönetim planı oluşturulması gerektiği düşünülmektedir. Bu amaçla çalışma kapsamında kentsel dönüşüm uygulamaları için yapısal atık yönetim planı önerisi geliştirilmiştir. Söküm/yıkım öncesi, söküm/yıkım ve söküm/yıkım sonrası olarak birbirini takip eden üç ana süreçten oluşan bu plana göre (Şekil 11);

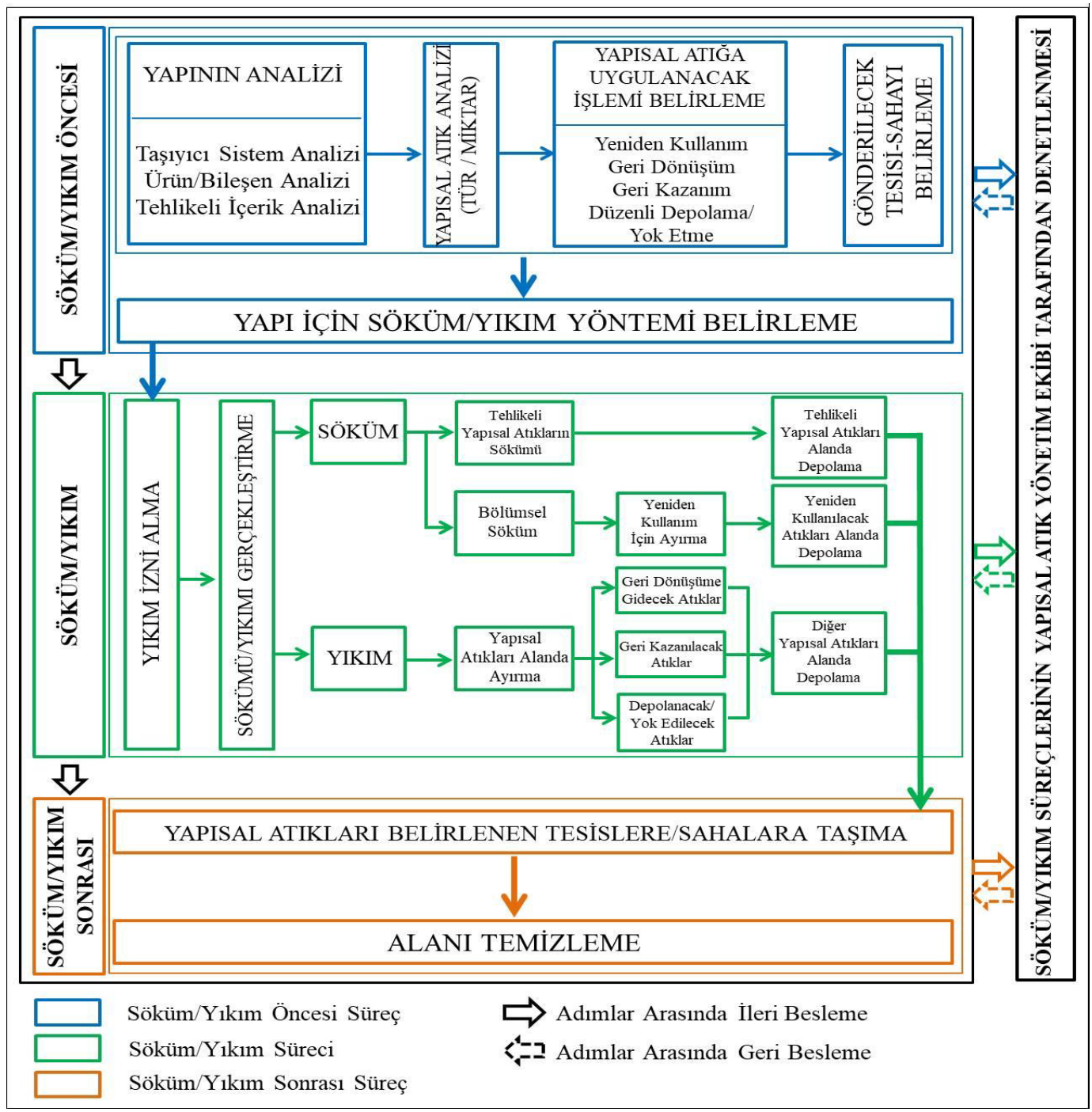

Şekil 11. Kentsel dönüşüm uygulamaları için önerilen yapısal atık yönetim planı 


\section{Söküm/yıkım öncesi süreçte,}

- Kentsel dönüşüm alanındaki yapılar belirlenmeli, her yapının taşıyıcı sistemi, ürünleri ve (varsa) tehlikeli içerik barındıran yapı ürünleri analiz edilmeli,

- Söküm/yıkım sonrasında oluşacak yapısal atıkların türü ve miktarı saptanmalı,

- Bu atıklara yeniden kullanım, geri dönüşüm, geri kazanım, düzenli depolama/yok edilme işlemlerinden hangisinin uygulanacağı ve uygulanacak işleme göre gönderilecek en yakın tesisler/sahalar belirlenmeli,

- Yapılan analizler doğrultusunda yapılar için söküm/yıkım yöntemine karar verilmelidir.

Söküm/yıkım sürecinde,

- Yıkım izni alınmasıyla birlikte süreç başlamalı,

- Öncelikle asbest gibi tehlikeli içerikler barındıran yapı ürünleri uzman kişiler tarafından gerekli önlemler alınarak sökülmeli, yeniden kullanılacak durumda olan bütün yapı ürünleri sökülmeli,

- Yapının geri kalanı için seçici yıkım yöntemi uygulanmalı, oluşan yapısal atıklar alanda geri dönüşüm, geri kazanım ve depolama/yok etme işlemleri için ayrılmalı,

- Oluşan bütün atıklar alanda uygun koşullarda geçici olarak depolanmalıdır.

Söküm/yıkım sonrası süreçte,

- Alanda özelliklerine göre sınıflandırılarak depolanmış olan bütün yapısal atıklar söküm/yıkım öncesi süreçte belirlenen tesislere/sahalara uygun koşullarda taşınmalı,

- Alan temizlenerek söküm/yıkım süreci tamamlanmalıdır.

Yönetim planındaki adımlara uygun olarak yürütülen söküm/yıkım süreçlerinin belediyeler bünyesinde oluşturulacak "Yapısal Atık Yönetim Ekipleri" tarafından denetlenmesi ayrıca önemli görülmektedir. Bu ekiplerin belediyelerin internet sayfalarında duyurulması, söküm/yıkım işini yüklenen firma yetkililerinin bu ekipler ile bağlantı kurması, bütün sürecin eşgüdümlü biçimde yürütülmesi önerilmektedir. Ayrıca geliştirilen/geliştirilecek olan yönetim planlarının gönüllülükten çok zorunluluklar çerçevesinde uygulanması önemli görülmektedir.

Kentsel dönüşüm çalışmalarında uygulanacak yapısal atık yönetim planı ile atık oluşumunun azalacağı, böylece

- Doğal kaynakların korunacağı,

- Çevre kirliliğinin azalacağı,

- Ekonomik kayıpların önüne geçilebileceği düşünülmektedir.

\section{TEŞEKKÜR}

2016-2017 Eğitim-Öğretim Yılı Bahar Yarıyılı’nda, Erciyes Üniversitesi, Fen Bilimleri Enstitüsü, Mimarlık Anabilim Dalı’nda açılan "MìM 505 Yapısal Atık Yönetimi" dersini alan öğrencilerden Nurbanu Atmaca, Ahmet Hasdal ve Murtaza Er'e bu çalışma kapsamında ilgili belediyelerde yaptıkları görüşmelerden dolayı teşekkür ederiz.

\section{KAYNAKLAR}

[1] ROBERTS, P., SYKES, H., Urban Regeneration: A Handbook (1st ed.), SAGE Publications Ltd., London, UK, 2000.

[2] DEMIRKIRAN, S., Türkiye'de Kentsel Dönüşüm Uygulamalarında Yerel Yönetimlerin Rolü: Bursa Büyükşehir Belediyesi Örneği, Yüksek Lisans Tezi, Trakya Üniversitesi, Sosyal Bilimler Enstitüsü, Edirne, Türkiye, 2008.

[3] KOCAMEMİ, G.N., Kentsel Dönüşüm Süreci Kızılçeşme Örnegi, Yüksek Lisans Tezi, MSGSÜ, Fen Bilimleri Enstitüsü, İstanbul, Türkiye, 2006.

[4] SALGIN, B., Yapı Yaşam Süreçlerinde Yapısal Atıkların Önlenmesine/Azaltılmasına Yönelik Tasarım Yaklaşımları ve Bir Model Önerisi, Doktora Tezi, YTÜ, Fen Bilimleri Enstitüsü, İstanbul, Türkiye, 2015.

[5] AKKAR, Z.M., "Kentsel Dönüşüm Üzerine Batı'daki Kavramlar, Tanımlar, Süreçler ve Türkiye", TMMOB Şehir Plancıları Odası Yayını, Planlama Dergisi, 36, 29-38, 2006.

[6] ATAÖV, A., OSMAY, S., "Türkiye'de Kentsel Dönüşüme Yöntemsel Bir Yaklaşım", METU Journal of Architecture, 24, 57-82, 2007.

[7] ESENTÜRK, M., İstanbul İli Örneğinde Kentsel Dönüşüm Uygulamaları, Yüksek Lisans Tezi, YTÜ, Fen Bilimleri Enstitüsü, İstanbul, Türkiye, 2009. 
[8] ÖZDEN, P.P., Yasal ve Yönetsel Çerçevesiyle Şehir Yenileme Planlaması ve Uygulaması: Türkiye Örneği, Doktora Tezi, İTÜ, Fen Bilimleri Enstitüsü, İstanbul, Türkiye, 2002.

[9] COUCH, C., FRASER, C., Introduction: the European Context and Theoretical Framework. In C. COUCH, C. FRASER, S. PERCY (Eds.), Urban Regeneration in Europe (pp. 1-16), Blackwell Publishing, Oxford, UK, 2003.

[10] UZUN, C.N., "Yeni Yasal Düzenlemeler ve Kentsel Dönüşüme Etkileri”, Planlama Dergisi, 2, 49-52, 2006.

[11] SALGIN, B., Brüt Beton, Brütalizm ve Türkiye Örnekleri, Yüksek Lisans Tezi, Erciyes Üniversitesi, Fen Bilimleri Enstitüsü, Kayseri, Türkiye,. 2007.

[12] MILANI, B., "Building Materials in a Green Economy Community-based Strategies for Dematerialization", Paper derived to the Biennial Conference of the Canadian Society for Ecological Economics, McGill University, Montreal, Canada, 2001.

[13] http://ec.europa.eu/environment/waste/index.htm (erişim tarihi 10.10.2017)

[14] COŞGUN, N., ESIN, T., "Kentsel Dönüşüm Sürecinde Yapısal Atık Yönetimi”, 5. Ulusal Katı Atık Yönetimi Kongresi, 70-77, Kocaeli, Türkiye, 2013.

[15] KIBERT, C.J., CHINI, A.R., "Introduction: Deconstruction as an Essential Component of Sustainable Construction", CIB Report Publication 252, Florida, 6-13, 2000.

[16] DENG, X., LIU, G., HAO, J., "A Study of Construction and Demolition Waste Management in Hong Kong”, Proceedings of the 4th International Conference on Wireless Communications, Networking and Mobile Computing, 1-4, Dalian, China, 2008.

[17] DORSTHORST, B.J.H., KOWALCZYK, T., "State of Deconstruction in the Netherlands", CIB Report, Publication 300, Florida, 162-180, 2005.

[18] WEISHENG, L., HONGPING, Y., "Off-Site Sorting of Construction Waste: What Can We Learn from Hong Kong?", Resources, Conservation and Recycling, 69, 100-108, 2012.

[19] YEUNG, A., "Construction and Demolition Materials Management in Hong Kong", Proceedings of the Institution of Civil Engineers: Municipal Engineer, 161, 43-49, 2008.

[20] SANCHEZ, I.G., LAURITZEN, E.K., "Integrated Decontamination and Rehabilitation of Buildings, Structures and Materials in Urban Renewal - A European Project for a Sustainable City Concept", Proceedings of the International RILEM Conference on the Use of Recycled Materials in Buildings and Structures, 265-274, Barcelona, Spain, 2004.

[21] SANCHEZ, I.G., LAURITZEN, E.K., "IRMA: a European Project for a Sustainable City Concept", Proceedings of the 4th International Conference on Urban Regeneration and Sustainability, 273-282, Tallinn, Estonia, 2006.

[22] ACAR, A., "Kentsel Dönüşüm ve Çevre", İzolasyon Dünyası, 99, 14-16, 2013.

[23] ALTINDAĞ, S., İstanbul'da Hafriyat Toprağı, İnşaat ve Yıkıntı Atıklarının Tersine Lojistik Yöntemiyle Alternatif Yönetim Planı, Yüksek Lisans Tezi, İTÜ, Fen Bilimleri Enstitüsü, İstanbul, Türkiye, 2011.

[24] T.C. Çevre ve Orman Bakanlığı, "Hafriyat Toprağı, İnşaat ve Yıkıntı Atıklarının Kontrolü Yönetmeliğı", 18.03.2004

[25] http://web.dcp.ufl.edu/ckibert/DeconstructionBook (erişim tarihi 15.10.2008)

[26] T.C. Çevre ve Şehircilik Bakanlı̆̆ı, "Yıkım İşlemleri ile Hafriyat Toprağı, İnşaat ve Yıkıntı Atıklarının Kontrolü Yönetmeliği Taslağı”, 20 Nisan 2017.

[27] TUNA TAYGUN, G., "Kentsel Dönüşümde Asbest Riski”, Mimarlık, 390, 78-81, 2016.

[28] http://www.csb.gov.tr/iller/kayseri/index.php?Sayfa=haberdetay\&Id=106584 (erişim tarihi 08.04.2017)

[29] Resmi Gazete'de yayımlanan 27.12.2016 tarih ve 2016/9706 sayll karar.

[30] www.sahabiyedonusum.com (erişim tarihi 26.03.2017)

[31] SALGIN, B., Kişisel Arşiv (fotoğraflama tarihi 16.10.2017).

[32] Resmi Gazete'de yayımlanan 16.10.2015 tarih ve 2015/8201 sayll karar.

[33] Melikgazi Belediyesi Kentsel Dönüşüm Müdürlüğü ve Ulaşım Hizmetleri Müdürlüğü personelleri ile yapılan görüşmeler, 24.03.2017 ve 17.04.2017.

[34] www.referansdonusum.com (erişim tarihi 24.03.2017)

[35] Resmi Gazete'de yayımlanan 16.10.2015 tarih ve 2015/8200 sayıll karar.

[36] Resmi Gazete'de yayımlanan 27.12.2016 tarih ve 2016/9708 sayll karar.

[37] Kocasinan Belediyesi Kentsel Dönüşüm Müdürlüğü personelleri ile yapılan görüşme, 24.03.2017.

[38] Kocasinan Belediyesi Kentsel Dönüşüm Müdürlüğü arşivi (erişim tarihi: 24.03.2017).

[39] Resmi Gazete'de yayımlanan 15.06.2015 tarih ve 2015/7859 sayll karar.

[40] Resmi Gazete'de yayımlanan 26.09.2016 tarih ve 2016/9286 sayll karar.

[41] Resmi Gazete'de yayımlanan 24.11.2014 tarih ve 2014/7031 say1l karar.

[42] Resmi Gazete'de yayımlanan 27.12.2016 tarih ve 2016/9725 sayll karar.

[43] Resmi Gazete'de yayımlanan 26.09.2016 tarih ve 2016/9285 sayll karar.

[44] Resmi Gazete'de yayımlanan 26.09.2016 tarih ve 2016/9284 sayll karar. 